\title{
Expedition medicine: A southern African perspective
}

\author{
R Hofmeyr, ${ }^{1,2}$ MB ChB, DipPEC, DA, MMed (Anaes), FCA (SA), FAWM; G Tölken, ${ }^{2,3}$ MA; \\ R De Decker, ${ }^{4} \mathrm{MSc}, \mathrm{MB}$ ChB, DCH, FCPaeds (SA), Cert Med Genet (Paeds) \\ 'Department of Anaesthesia and Perioperative Medicine, Faculty of Health Sciences, University of Cape Town, South Africa \\ ${ }^{2}$ WildMedix, Cape Town, South Africa \\ ${ }^{3}$ Mountain Club of South Africa, Mountain Rescue, Hottentots-Holland Section, Cape Town, South Africa \\ ${ }^{4}$ Department of Paediatrics and Child Health, Faculty of Health Sciences, University of Cape Town, and Red Cross War Memorial \\ Children's Hospital, Cape Town, South Africa
}

\begin{abstract}
A growing number of people are undertaking expeditions and adventure travel to previously inaccessible areas. The risks posed by increasing accessibility of remote regions and interest in extreme sports have not been fully obviated by modern equipment and communications. Therefore, there remains a requirement for medical care during wilderness expeditions, for which expectations and formal standards continue to increase. Expedition medicine should take cognisance of the predicted problems, plan for contingencies, and be practised pragmatically in austere settings. Southern African medics have a broad skill set, which makes them ideally suited to the field, but they should seek to understand the epidemiology of expeditions in different environments, undergo specialised training, and become involved in all phases of planning and execution of an expedition. Routine general practice complaints and accidental trauma are ubiquitous; travel medical issues such as blisters, diarrhoea, insomnia, sunburn and dehydration occur commonly; area/activity-specific issues such as infectious disease risks and altitude illnesses must be addressed; and women's health and dental problems are frequently overlooked. The expedition medic plays a wide range of roles, and should have knowledge and skills to match the requirements of the expedition. Fortunately, many resources exist to assist medics in becoming competent in the field.
\end{abstract}

S Afr Med J 2017;107(8):659-663. DOI:10.7196/SAMJ.2017.v107i8.12676

\author{
'Have you suffered, starved and triumphed, \\ grovelled down, yet grasped at glory, \\ Grown bigger in the bigness of the whole? \\ "Done things" just for the doing, \\ letting babblers tell the story, \\ Seeing through the nice veneer the naked soul? \\ Have you seen God in His splendours, \\ heard the text that nature renders? \\ The simple things, the true things, the silent men who do things - \\ Then listen to the Wild - it's calling you.' \\ (Call of the Wild - Robert Service)
}

\section{Scenario}

A group of friends invites you to join a month-long overland fourwheel-drive trip through southern Africa. The three-vehicle convoy will visit wilderness areas in four countries, in many places spending several days between settlements, traversing remote game parks and unfenced camps in the bush. As you are the only doctor in the group, they offer to cover your costs if you serve as the expedition's medic. Eager for an adventure, you accept quickly. Only later do you begin to consider the implications of this role. What should you take with you? What mishaps and illnesses should you prepare for? How will you treat, transport or evacuate a member of the team? Suddenly, 'winging it' no longer feels like an adequate strategy.

\section{Background}

An expedition is described as a journey undertaken with a specific purpose, particularly for war, research, or exploration. Fortunately, as our antagonistic conquests for new territories have decreased, humans have sought to travel to remote regions for reasons of both scientific and, increasingly, personal discovery. Currently, many individuals undertake expeditions seeking personal challenges, promotion of worthy charitable causes, and extreme adventure activities. While detractors may accuse expedition participants of doing things '.. just for the doing', many actively seek out adversity in exchange for the beauty rendered by nature, and to see '... through the nice veneer the naked soul'. As technology and modern amenities steadily shrink the world into a global village, areas and destinations that would previously have required large, lengthy expeditions to reach can now be visited easily by adventure tourists with adequate financial means. Unfortunately, this may have decreased the average levels of skill and experience of participants. ${ }^{[1]}$ Although modern equipment and communications have made wilderness expeditions much safer, they have not been able to obviate the vagaries of extreme conditions, fickle weather, thin air or gravity. When we listen to the call of the wild and explore far from formal healthcare systems, we must be prepared for medicine to travel with us.

Austerity does not constitute an excuse for poor care; 'making do' on ingenuity alone is not sufficient. Wilderness and expedition medicine, therefore, is as purposeful as the expedition itself: predicted, planned, and pragmatically performed. While expedition environments may differ dramatically - from seething oceans to desolate deserts, tropical jungles to frozen mountain peaks, and even to space - the unifying characteristics of expedition medicine remain the same: the patient and practitioner are in a remote location (in time and/or distance) under unusual physical and psychological demands (through exertion or environmental stressors). There is strong reliance on both clinical examination and good judgement within the context of location, available materials, and team dynamics. Resource constraints require rationing, ingenuity and improvisation. Fortunately, all of these characteristics are familiar to medics who have trained and practised in southern Africa.

Globally, wilderness medicine has grown organically with little organisation, driven by the needs of groups in a wide variety of environments. Traditionally, expedition doctors were wilderness 
enthusiasts with specific outdoor skills, who provided medical services as enthusiastic amateurs. Particularly in North America and Europe, however, these roles have become more formalised, and as expectations grew, medical standards (and ultimately research in the field) have expanded and continue to evolve rapidly. ${ }^{[2]}$ Despite a strong history of participation in worldwide expeditions by South Africans, earlier development of wilderness and expedition medicine in South Africa (SA) was hampered by the limitation of international travel due to sanctions against the apartheid regime. However, the generally broad experience and skill sets of SA doctors make them well suited to provide care in extreme environments.

\section{Epidemiology of expedition medicine}

To the uninitiated, providing medical care on expeditions conjures up images of wild and venomous animal attacks, frostbite, spectacular falls and outlandish tropical diseases. While isolated locations and adverse environments do carry particular concerns, it is more important for the expedition medic to be prepared for the ordinary than the obscure. Indeed, it is more likely that a participant will suffer injury as a result of a motor vehicle collision on the way to the trailhead rather than any other expedition-related risk. ${ }^{[3]}$ Generally, the epidemiology of wilderness illness and injury can be considered in three classes of decreasing frequency: day-to-day 'general practitioner' ailments, travel medicine issues, and expedition/environment-specific problems.

On all but the largest expeditions, the medic is likely to be the only medical professional, and will therefore bear the brunt of any and all consultations. Immediate, free and unlimited access may encourage participants to consult the expedition medic for complaints with which they would not have presented to their general practitioner at home. Simple colds and influenza, headaches, muscle aches and strains, inconsequential gastrointestinal upsets, minor bumps and scrapes are common, and can be a drain on expedition medical supplies if treated aggressively. ${ }^{[4]}$ Furthermore, consultations for women's health issues and dental hygiene (especially on longer expeditions) are frequent, and often beyond the scope of experience of the practitioner. Therefore, while learning about trypanosomiasis and Crimean-Congo haemorrhagic fever for travels in Africa may seem desirable, acquiring competence in field management of toothache and caries is more important. To combat exhaustion of simple supplies (and encourage team members to use them sparingly), it is effective to encourage all participants to carry a small first-aid kit containing items such as adhesive plasters, analgesics, antispasmodics, rehydration solution, basic dressings and an antiseptic. Adding a few basic trauma supplies - for instance, a structural aluminium malleable (SAM) splint, trauma dressing and crêpe bandage - allows these kits to be pooled to manage emergencies, and reduces the bulk that must be carried by the expedition medic.

After routine general practitioner complaints, travel medicine issues are the most frequently encountered on expeditions. Foremost among these is traveller's diarrhoea, which is frequently caused simply by a change in dietary habits while on an expedition, or exposure to benign pathogens. However, gastroenteritis can be rapidly spread within a party unless meticulous attention is paid to personal hygiene, handwashing, clean water provision, and food preparation. Any gastrointestinal upset causing dehydration or lasting $>48$ hours should trigger symptomatic treatment and strong consideration of antimicrobials, especially after 72 hours. Powdered or effervescent sports drink preparations are commonly carried on expeditions, and can be used to both replace lost electrolytes and mask the taste of water purification tablets.

Other frequent travel issues include poor sleep (due to jet lag, unfamiliar environments or sharing quarters with noisy sleepers), blisters, and manifestations of solar exposure such as sunburn and dehydration. While simple exhaustion often solves the insomnia, it should be remembered that poor sleep at high altitudes can be both a consequence of poor acclimatisation and a diagnostic criterion for acute mountain sickness (AMS). Early initiation of prophylaxis/ treatment with acetazolamide may profoundly improve this situation. Blisters, sunburn and dehydration are best managed by proactive prevention.

Expedition-specific medical problems are determined by the nature of the activities, destination and wilderness environment. For instance, high-altitude expeditions require planning for acclimatisation and high-altitude illness, ${ }^{[5,6]}$ but should also anticipate local and systemic cold exposure injuries, ${ }^{[7]}$ and accidental trauma. In the African context, this is likely to include infectious disease. Malaria is a common threat that should not be discounted. Consideration should also be given to other transmissible conditions such as Dengue fever, cholera, typhoid, yellow fever and meningitis. Finally, the specific risks of specialised expedition tasks must be anticipated, such as dysbarism or decompression illness during diving.

\section{The role of the expedition medic}

Expedition medics clearly need a wide range of competencies to fulfil an unusually broad scope of roles, as described in Table 1.

\section{Expedition medic qualifications and competencies}

The nature of expedition medicine attracts individuals from diverse backgrounds, both personally and professionally. Although many expeditions may wish to be accompanied by a qualified expedition doctor, medics from fields such as nursing, prehospital or military field medicine and physiotherapy with appropriate skills and training can and do provide excellent care in the field ${ }^{[8]}$ Indeed, the breadth and depth of wilderness experience of the individual may be of more relevance than their specific medical qualification, and for some wilderness activities that carry a low risk and are without lengthy delays for evacuation, an expedition member who has been trained in advanced wilderness first aid may suffice.

Regardless of background, there are essential requirements for competency as an expedition medic. First and foremost, the medic should be competent to undertake the activities and cope well with the demands of the expedition, being comfortable to care for themselves in the specific wilderness environment. Adequate fitness and technical skill with regard to the expedition activities (e.g. mountaineering or kayaking skills) are essential. A doctor who cannot ski is a poor choice for a polar crossing, as is a nurse prone to motion sickness on a sailing trip.

Secondly, the medic must have the medical knowledge and skills to competently manage the most likely illnesses and injuries that may occur during the expedition. Generally, SA doctors have a broad skill set and can perform a wide range of minor procedures, which makes them well suited to serve on expeditions. However, as the itinerary becomes increasingly isolated from accessing a formal healthcare system, so does the level of intervention required to be practised in the field. A prospective wilderness medic should consider carefully where they may need to supplement their skills before departure (Fig. 1).

Finally, the expedition medic must consider his or her ability to perform medical care within an austere or adverse wilderness environment, with very limited support, possibly without the option of consulting colleagues, and with very limited equipment. It is a worthwhile exercise to perform wilderness simulations of potential medical emergencies, or to obtain formal wilderness medicine training, before embarking on an expedition. Crucially, wilderness 


\section{Table 1. Roles of the medic before, during and after an expedition}

\begin{tabular}{|c|c|c|}
\hline \multirow{4}{*}{ 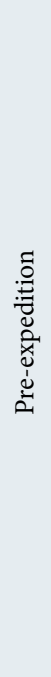 } & Planning & $\begin{array}{l}\text { Integrate medical considerations into all aspects of planning } \\
\text { Build close working relationship with expedition leadership } \\
\text { Learn about the area, activities, challenges and risks } \\
\text { Consider locally occurring infectious diseases: prevention, prophylaxis and specific treatments (if required) } \\
\text { Consider all facets and periods of expedition, and formulate a medical evacuation plan for each } \\
\text { area/activity/period } \\
\text { Advise participants on suitable medical and evacuation insurance }\end{array}$ \\
\hline & Screening & $\begin{array}{l}\text { Consider whether medical barriers to participation exist } \\
\text { Perform appropriate screening and advise participants }\end{array}$ \\
\hline & Provisioning & $\begin{array}{l}\text { Review/plan food and water provisioning } \\
\text { Review/plan hygiene requirements } \\
\text { Plan and pack medical supplies }\end{array}$ \\
\hline & Training & $\begin{array}{l}\text { Acquire or improve any specifically required medical skills } \\
\text { Ensure that the medical team has appropriate and adequate wilderness skills and fitness to take part in } \\
\text { expedition activities } \\
\text { Where possible, provide medical or wilderness first-aid training to expedition participants }\end{array}$ \\
\hline \multirow{2}{*}{ 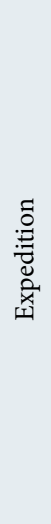 } & Prevention & $\begin{array}{l}\text { Maintain close liaison with expedition leadership } \\
\text { Build rapport with participants } \\
\text { Daily review of hygiene, food and water provisions } \\
\text { Ongoing simple preventive medicine: hydration, stretching, sun protection, infectious disease prophylaxis, } \\
\text { hand-washing, dental and other personal hygiene, sexual health } \\
\text { Regular 'clinic' times to ease access (but maintain medic sanity!) } \\
\text { Consider ongoing first-aid training (can be scenario-based) }\end{array}$ \\
\hline & Intervention & $\begin{array}{l}\text { Ensure appropriate care is available to local staff and local people } \\
\text { Manage routine medical issues during the expedition } \\
\text { Provide psychological support to participants } \\
\text { Maintain adequate records of consultations, treatments, challenges, supplies and other information, which } \\
\text { may be of future use } \\
\text { Manage medical emergencies }\end{array}$ \\
\hline \multirow{2}{*}{ 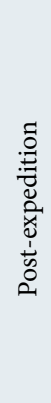 } & Follow-up & $\begin{array}{l}\text { Advise participants with regard to medical conditions (eg. infectious diseases) which may only present in the } \\
\text { weeks following return from the expedition } \\
\text { Follow up on any medical problems which presented during the expedition, especially those requiring } \\
\text { evacuation or early termination of participation }\end{array}$ \\
\hline & Document & $\begin{array}{l}\text { Compile and submit an expedition medical report } \\
\text { Document the supplies (medicines and disposables) used during the expedition, and consider making } \\
\text { recommendations for future trips of the same nature } \\
\text { Consider publication of useful information and findings in the literature } \\
\text { Engage in networks of expedition medicine practitioners (e.g. wilderness medicine societies and online } \\
\text { discussion groups) to share experience and help advance the speciality }\end{array}$ \\
\hline
\end{tabular}

practitioners need to be willing and able to think and act beyond the confines of their usual practice ${ }^{[9]}$ (Fig. 2).

Until recently, there was little guidance on the competencies required for wilderness and expedition medicine. While numerous specialty courses exist (typically directed at specific environments, such as polar, mountain or jungle medicine) and there are several postgraduate wilderness medicine qualifications available worldwide, there has been little standardisation of requirements. In 2015, the Faculty of Pre-Hospital Care, Royal College of Surgeons of Edinburgh published a consensus report on medical provision for wilderness medicine. ${ }^{[10]}$ This includes recommendations on the qualification levels of practitioners for wilderness activities, based on the perceived level of risk of the expedition, and the delay in accessing a higher level of outside care. At the most basic level, this person might be a non-medical member of the party with first-aid training. Where risk is higher, or delay to definitive care exceeds 12 hours, a doctor or advanced allied practitioner with adequate diagnostic and procedural skills and basic wilderness training is recommended. Qualified and experienced expedition doctors are recommended for remote or high-risk expeditions.

\section{Expedition medical kits}

Due to kit size and weight limitations inherent in participation in wilderness expeditions, the bag of the expedition medic must be packed with careful consideration and finesse. To keep the medical equipment within practical confines, the key determining factor becomes versatility of equipment and medication, rather than highly advanced niche applications. Every item should be either irreplaceable or have multiple uses. In addition to sufficient supplies for trauma and medical risks due to expedition area, remoteness, biome, altitude, 


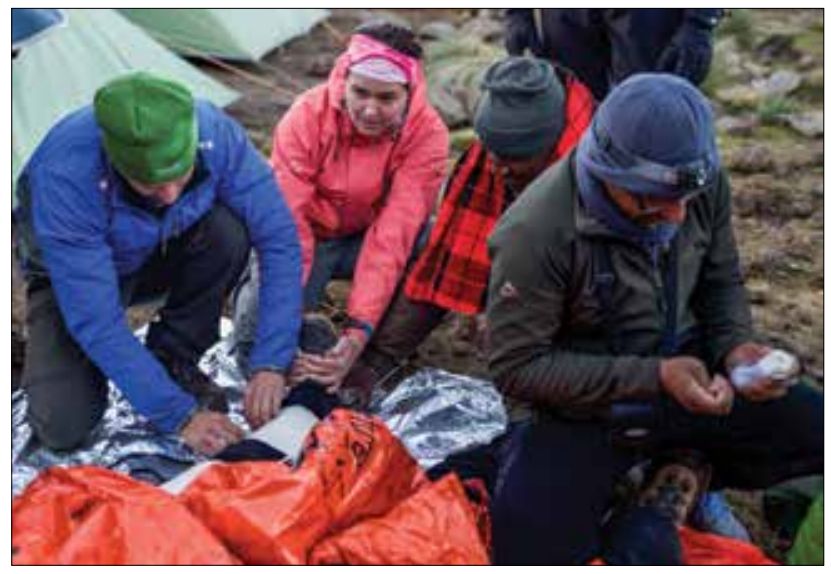

Fig. 1. Mountain guides and doctors undertaking a mountain medicine training expedition on Mount Kilimanjaro participate in field management of a simulated casualty. (Photo: Dr Chanèl Rossouw, with permission.)

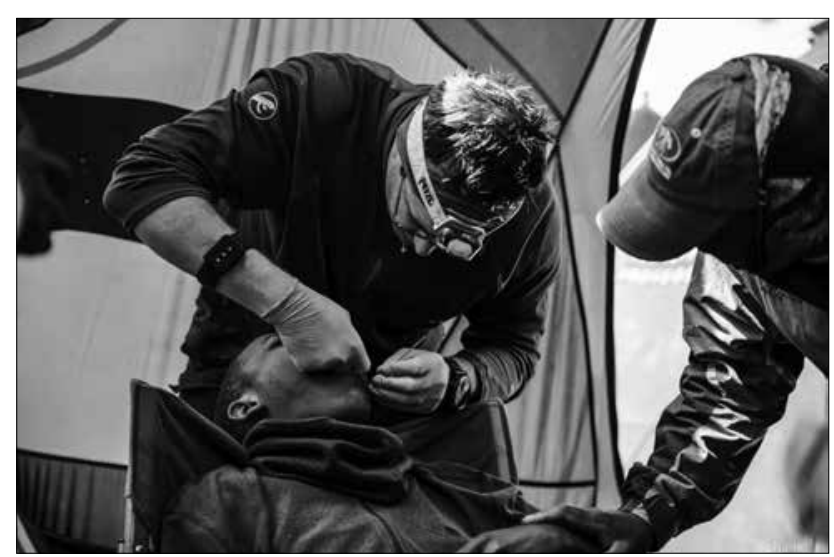

Fig. 2. An expedition medic performing field removal of a septic dental root after tooth avulsion at high altitude. Acquisition of a broad skill set is essential for providing pragmatic wilderness medicine. (Photo: Dr Chanè Rossouw, with permission.)

duration and main activities, the medic should consider specific risks of the expedition participants. Taking advanced airway equipment, for example, should only be considered if the medic is sure that once in use, advanced airway management in the wilderness can also be sustained while waiting for a prolonged evacuation. Practical considerations such as temperature and water/humidity exposure of equipment and medications also come into play. This can be mitigated by packing supplies into waterproof containers (or simple zip-lock plastic bags) with accurate labelling, clustering/compartmentalising into practical sets such as airway management, haemorrhage control, wound closure, and pain management. This ensures that access to appropriate supplies is swift and easy in the field. As the medic on an expedition is as prone to all risks as every other expedition member, providing advice and training to selected expedition members on the contents, structure and usage of the expedition medical kit is advisable. This ensures continuity of medical care should the primary medic be incapacitated.

\section{Ethics in expedition medicine}

It is important that the medic is willing to sacrifice personal goals during the expedition to provide care to participants. This means that the expedition doctor should not be financially invested in the expedition - whether linked to a successful outcome, or because he/she has paid a fee to attain the expedition goal - as this compromises their decisionmaking.
Expeditions are becoming safer, but society is also much less tolerant of risk. Every effort must be made to ensure that expedition participants have a realistic perception of the inherent dangers of the destination and activities, and are especially cognisant of the limited medical care that can be provided in the field. For example, the recent furore surrounding the death of a celebrity and lack of helicopter rescue during the night on Mount Kilimanjaro illustrates a pervasive lack of understanding of the local rescue capabilities in that area. The expedition medic must be au fait with available facilities on the ground, and help potential participants to understand the risks in relation to their goals, so that they can make an informed decision on participation.

Expedition doctors should be very aware of the challenges of balancing patient confidentiality with overall safety and expedition goals. Prior to an expedition, this may require significant efforts to gain the trust of prospective participants to disclose conditions that they feel may jeopardise their chances of being selected, and counselling to disclose potential medical risks to the expedition leadership. It is the contention of the authors that very few medical conditions are a complete barrier to participation in wilderness activities, provided the medic and participant are adequately informed. With full understanding of the risks, and informed consent, individuals should be able to experience the entire spectrum of challenges in the wilderness.

On an expedition, it can be difficult to create an environment in which participants can consult in private. It is useful to site the expedition doctor's tent/accommodation on the outskirts of the camp, and in such a way as to allow privacy of interactions. Medics should be aware - especially at night - of the scant protection provided by tent walls. A final set of ethical challenges during expeditions centres upon denial of treatment and provision of futile care. In contrast to urban medicine, an expedition participant who declines or actively ignores medical advice can place fellow team members at risk. A more paternalistic care relationship is therefore required. Ideally, a consensus regarding management of these cases should be reached with the expedition leadership.

\section{Resources for expedition medics}

Fortunately, the increasing recognition of expedition medicine as a specialised field has led to the proliferation of good-quality resources for current and prospective expedition medics. These include professional groups such as the Wilderness Medical Society (www.wms.org) and the International Society for Mountain Medicine (www.ismm.org); online repositories such as Adventure Medic (www.theadventuremedic.com) and Explorers Connect (www.explorersconnect.com); mountaineering organisations such as the Mountain Club of South Africa (cen.mcsa.org.za); professional wilderness medicine companies such as WildMedix (www.wildmedix. com); and health organisations such as the Centres for Disease Control and HealthMap (www.cdc.gov; www.healthmap.org). Peer-reviewed research and academic articles in this field can be obtained in journals such as the Wilderness and Environmental Medicine Journal, and High Altitude Medicine and Biology. There are also educational resources such as wilderness medicine podcasts (www.wemjournal.org).

The expedition doctor who prefers reading textbooks should consider the focused manual, Expedition and Wilderness Medicine, by Hudson and Knox, ${ }^{[11]}$ the practical and comprehensive Oxford Handbook of Expedition and Wilderness Medicine, edited by Johnson et al. ${ }^{[8]}$ or the definitive encyclopaedia in the field, Auerbach's Wilderness Medicine. ${ }^{[9]}$

\section{Scenario resolution}

Realising you have bitten off a little more than you can chew, you make two worthwhile investments: the electronic copy of an expe- 
dition and wilderness medicine textbook, and a hands-on course with an experienced company. The resulting increased understanding of the specific risks of the area and practical skills allow you to pack appropriate medical supplies for the expedition. In a remote camp in Botswana, one of the group who has been unwell with undifferentiated symptoms faints into the fire, sustaining seconddegree burns. You are able to provide effective immediate care, and, using a predetermined plan, evacuate her to Gaborone. By the time she arrives, you have already diagnosed the malaria that caused her collapse using a disposable rapid diagnostic kit, and have initiated treatment. After initial stabilisation, she is repatriated to SA and makes a full recovery while you re-join the expedition and enjoy an uneventful completion.
1. Dallimore J, Mason NP, Moore J. Expedition medicine. In: Auerbach PS, Cushing T, Harris NS, eds.

Auerbach's Wilderness Medicine. 7th ed. Philadelphia, PA: Elsevier, 2017.
. Imray CH, Grocott MP, Wilson MH, et al. Extreme, expedition, and wilderness medicine. Lancet 2015;386(10012):2520-2525. https://doi.org/10.1016/S0140-6736(15)01165-4

2015;386(10012):2520-2525. https:///doi.org/10.1016/S0140-6736(15)01165-4 562. https://doi.org/10.1177/014107680009301102

McIntosh SE, Leemon D, Visitacion J, et al. Medical incidents and evacuations on wilderness expeditions. Wilderness Environ Med 2007;18(4):298-304. https://doi.org/10.1580/07-WEME-OR-093R1.1

5. Hofmeyr R, Meyer W, James M, et al. Recognising and mitigating the risk of altitude-related illness. S Afr Med J 2016;106(9):834-835. https://doi.org/10.7196/SAMJ.2016.v106i9.11389

6. Hofmeyr R, Tölken G, De Decker R. Acute high-altitude illness. S Afr J Med 2017;107(7):556-561. https://doi.org/10.7196/SAMJ.2017.v107i7.12612

Hofmeyr R. Wilderness cold-exposure injuries: An African perspective. S Afr Med J 2017;107(7):566570. https://doi.org/10.7196/SAMJ.2017.v107i7.12610

8. Johnson C, Anderson S, Dallimore J, et al. Oxford Handbook of Expedition and Wilderness Medicine. 2nd ed. Oxford: Oxford University Press, 2015.

9. Auerbach PS, Cushing T, Harris NS, eds. Auerbach's Wilderness Medicine. 7th ed. Philadelphia, PA Elsevier, 2017

10. Mellor A, Dodds N, Joshi R, et al. Faculty of Prehospital Care, Royal College of Surgeons Edinburgh guidance for medical provision for wilderness medicine. Extrem Physiol Med 2015;4:22. https://doi. org/10.1186/s13728-015-0041-

11. Hudson S, Knox C. Expedition and Wilderness Medicine. Devon, UK: Expedition Medicine Ltd, 2006. 